\title{
Tecnologia no Desenvolvimento da Arte Interativa
}

\section{Technology in the Development of Interactive Art}

\author{
Gabriela Bonifacio dos Santos \\ Universidade Federal do Rio de Janeiro, Brasil \\ gabrielabonifacio.arq@gmail.com \\ Marinah Raposo \\ Universidade Federal do Rio de Janeiro, Brasil \\ marinah.raposo@gmail.com
}

\author{
Roberto Da Matta \\ Universidade Federal do Rio de Janeiro, Brasil \\ robertodamatta@live.com \\ Caio Cavalcanti \\ Universidade Federal do Rio de Janeiro, Brasil \\ caio.canti@gmail.com
}

\begin{abstract}
This article is the result of a project that has been developed in ten days during an academic workshop. The goal was to overcome the force of gravity by producing an environment sensitive to human actions. The action indicated to the group, "soil peeling", was conceptually idealized by creating an atmosphere that had the ability to subvert the force of gravity. The premise of the project was to support a critical attitude towards anthropocentric movement by emphasizing the individualistic character inherent to contemporary human being. This attitude has been represented by reversing the forces hierarchy. The power to control gravity was then assigned to the agent and, while they were in touch with the installation, they would have full control over a natural phenomenon and could handle it in their favor.
\end{abstract}

Keywords: Parametric design; Digital manufacturing; Responsive environment; Rapid prototyping; Anthropocene.

\section{Introdução}

Atualmente, arquitetura, design e arte vêm sendo conectados à ciência da computação com objetivo de desenvolver artefatos interativos capazes de responder aos agentes de modo autônomo, poético e sensível. Equipes criativas e inovadoras que tendem a ter um caráter multidisciplinar, agregam competências complementares na realização de tarefas respondendo às demandas de desenvolvimento de hardware e software e assim, permitindo a ampliação de repertório em todas as áreas envolvidas. "Os processos de produção associados às tecnologias computacionais também vêm permitindo uma maior aproximação entre o projeto e a manufatura dos artefatos, viabilizando a experimentação em diversas áreas do design de produto e arquitetura" (Bruscato, 2011). Se trata de uma arquitetura que reflete a tecnologia e a cultura dos tempos atuais, em que os meios digitais estão sendo cada vez mais usados nas fases de prospecção e desenvolvimento e não mais apenas como um instrumento de representação de projeto. Modelos conceituais, paramétricos, generativos e de desempenho têm auxiliado o processo otimizando o ciclo produtivo e possibilitando 0 ganho de eficiência. Representar, manipular, analisar e materializar os artefatos se torna uma tarefa complementar e garante diversas experimentações principalmente quando associadas às plataformas open-source, com softwares e hardwares acessíveis à um numero maior de projetistas e com isso encorajando a produção de artefatos responsivos.

A repercussão deste movimento tecnológico estimulou o processo de informatização e modernização dos núcleos de prototipagem dentro e fora das universidades. Os laboratórios tiveram seus espaços complementados com equipamentos apropriados para a produção de artefatos digitalmente programados. Dentro desse contexto, este artigo tem como objetivo descrever uma metodologia teóricoprática que foi aplicada durante o desenvolvimento de um elemento responsivo no decorrer de um workshop acadêmico organizado pelo Laboratório de Modelos (LAMO) da Universidade Federal do Rio de Janeiro (UFRJ). Esse estudo relata a experiência da oficina, avalia e apresenta 0 processo de execução do projeto e os resultados obtidos.

\section{Metodologia}

\section{O workshop}

O workshop que motivou este artigo se desenvolveu ao longo de dez dias e tinha como objetivo principal superar a força da gravidade através da produção de um ambiente sensível as ações humanas. Durante o processo, a equipe organizadora demonstrou diferentes mecanismos e possibilidades de como concretizar o desafio proposto. Inicialmente foram realizadas palestras que apresentaram os objetivos esperados durante $o$ andamento do curso e alguns trabalhos desenvolvidos a partir das ferramentas selecionadas para 0 workshop. Em seguida, foi aberto um espaço para debates e pesquisa. Sequencialmente a equipe introduziu os softwares que seriam utilizados por meio de aulas de Rhinoceros associado ao Grasshopper em interação com o hardware de programação e circuitos do Arduino.

Foram sorteados quatro grupos de cinco pessoas cada qual com um conceito que deveria ser utilizado para pensar num mecanismo desafiador da gravidade. O grupo responsável pelo trabalho que deu origem a este artigo recebeu a ação de "despegar do solo". O termo "despegar" gerou questionamentos por conta da interpretação da palavra que foi entendida como "desprender-se" do solo, como uma ação que estivesse agindo contra as forças convencionais da gravidade. Seguinte as discussões e pesquisas de 
possibilidades de como materializar o conceito, o grupo idealizou uma forma constituída por uma superfície que pudesse ser deformada enquanto estivesse em interação com o individuo. Este plano foi fragmentado para garantir maior organicidade nos movimentos e resultou um conjunto de partículas que comportavam uma unidade. Em seguida, o grupo iniciou análises que objetivavam estudar maneiras de movimentar as partículas sem individualizá-las.

O tempo disponível para o desenvolvimento do artefato era reduzido, então, para assegurar o bom andamento do projeto de cada grupo, todos os dias deveria ser apresentado uma evolução em relação ao dia anterior. Nesse sentido, para garantir o ritmo, cada integrante da equipe se tornou responsável pela execução de uma tarefa diferente, para que então, todas as etapas de prototipagem e programação pudessem ser concluídas a tempo. Estudos em maquetes com diferentes proporções geométricas evidenciaram as necessidades e ressaltaram as possibilidades dos diferentes movimentos que poderiam ser obtidos. As especificidades e a quantidade limitada dos materiais disponíveis restringiram algumas ações projetuais que, em contrapartida, atuaram como fatores estimulantes na produção criativa e sustentável em função da reutilização e redução do custo através da otimização da quantidade de material utilizado.
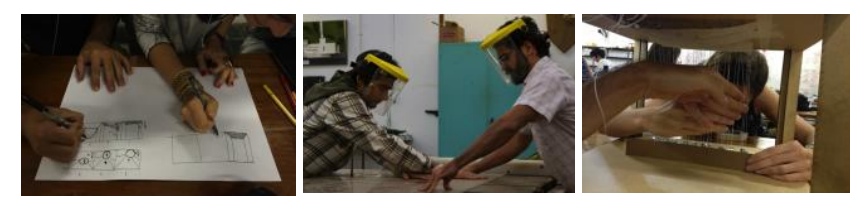

Figura 1: divisão de tarefas no grupo.

\section{Desenvolvimento da ideia}

O processo se iniciou a partir do método brainstorming para explorar e estimular a capacidade criativa dos integrantes do grupo. As ideias foram apresentadas em forma de croquis acompanhados de palavras-chave e diagramas e foram discutidas e analisadas em função das características desejadas e também da sua viabilidade em função do tempo e materiais disponíveis para execução. O bom andamento do processo de criação do grupo se deu em função da igualdade de oportunidade que cada integrante teve em explorar e expor as suas ideias e, como consequência dessa lógica, a equipe apresentou um grau de interação bastante positivo desde o início. O desafio dessa etapa foi compilar todos os pensamentos em prol de um único objetivo para então conseguir alcançar um denominador comum. Nesse momento foram definidas as principais características de interação entre o artefato responsivo e o agente.
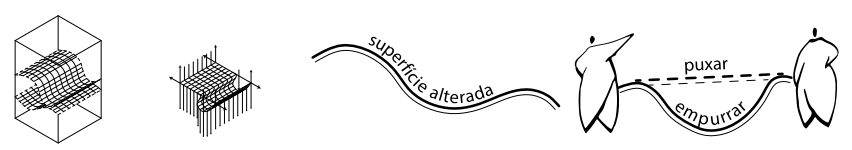

Figura 2: croquis de estudos do movimento da superfície.

A ação indicada ao grupo, "despegar do solo", foi inicialmente consolidada através da contextualização do tema e conceitualmente idealizada através da criação de uma atmosfera que tivesse a capacidade de subverter a atuação da gravidade. O projeto teve como premissa corroborar uma postura crítica frente ao movimento antropocêntrico ao enfatizar o caráter individualista inerente ao homem contemporâneo. O Antropocentrismo é uma concepção que considera que o universo deve ser avaliado de acordo com a sua relação com o homem, sendo que as demais espécies, bem como tudo mais, existem para servi-lo (Couto, 2009). O antropocentrismo coloca o homem no centro do universo, postulando que tudo o que existe foi concebido e desenvolvido para a satisfação humana. Essa atitude foi representada no projeto através de uma inversão na hierarquia de forças. O poder de controlar a gravidade foi então atribuído ao individuo e enquanto estivesse em contato com a instalação teria o domínio pleno sobre um fenômeno da natureza e poderia manejá-la a seu favor. O fenômeno proposto "chuva" foi simulado através de partículas que se moviam conforme a interação do agente ativo.

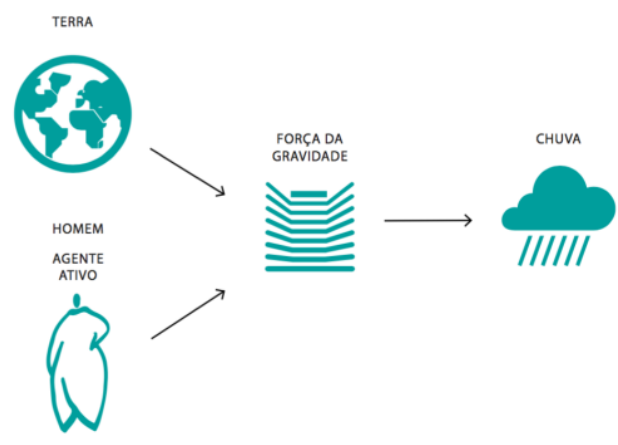

Figura 3: esquema da proposta de atuação em relação a força da gravidade.

$\mathrm{Na}$ etapa seguinte, o objetivo foi buscar referências para ilustrar a ideia do movimento de partículas combinado a atuação humana. Nesse momento foram investigadas questões como: mecânica dos movimentos, design da estrutura, materialidade e princípios de interação. Durante a pesquisa foi observado que a maioria dos projetos que movimentavam partículas tinham um sistema mecânico muito complexo comparado ao que poderia ser desenvolvido durante o workshop. Esses sistemas trabalhavam com um grande número de motores e roldanas, assim, o desafio do grupo consistia em otimizar essa quantidade para criar um sistema mecânico mais simples e inovador para o artefato em desenvolvimento. Outro ponto discutido durante as análises foi o aspecto que a instalação deveria ter e como o design estrutural deveria se relacionar com o elemento principal. A primeira possibilidade era transformar a estrutura de suporte e a superfície de partículas numa peça de design única e ao mesmo tempo imponente esteticamente configurada por peças personalizadas e encaixes complexos. A segunda possibilidade era direcionar o foco para a superfície de partículas através da construção de uma armação neutra com capacidade estrutural suficiente para dar suporte ao sistema mecânico. Após algumas discussões em relação ao design do artefato, o grupo identificou que "leveza" deveria caracterizar o objeto final, já que as partículas representariam um elemento de aspecto leve, logo, a segunda opção foi a escolhida. 


\section{Procedimentos práticos}

Posterior a etapa de definição do design, alguns elementos foram ensaiados para comprovar a efetividade estética e mecânica do artefato. Um dos aspectos testados foi se a estrutura poderia de fato garantir a leveza imaginada pelo grupo ao mesmo tempo que proporcionasse suporte para o mecanismo. Outro ponto foi identificar através de testes de dimensionamento a proporção geométrica ideal para que 0 plano de esferas se comportasse como previsto. Além disso foram experimentados diferentes tipos de materiais para cada componente e os meios de interação possíveis. $\mathrm{Na}$ produção de modelos para experimentos foram levados em consideração os materiais, a estrutura, a mecânica, os sistemas eletrônicos e os meios de interação.

\section{Testes de materiais: estrutura, cabos e partículas}

Os testes preliminares foram realizados com os materiais que estavam acessíveis naquele determinado momento. $\mathrm{O}$ primeiro modelo produzido tinha como propósito confirmar se a deformação da superfície de partículas iria corresponder ao comportamento idealizado. Os materiais utilizados neste protótipo serviram para ilustrar os aspectos principais que cada elemento deveria ter. Os cabos foram representados por linha de pipa e as esferas por bolinhas modeladas manualmente com massa Durepoxi. Os fios foram organizados através de uma placa de plástico composta por uma trama de círculos furados.
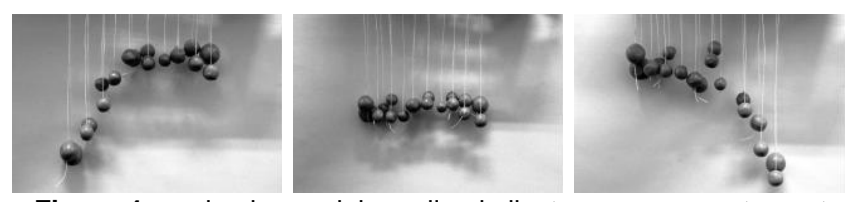

Figura 4: o primeiro modelo realizado ilustra com comportamento das esferas.

No segundo modelo a estrutura já havia sido pensada como um suporte de quatro cantos que pudesse dispor os elementos que iriam manipular o ponto de convergência dos fios. A armação foi modelada em Solidworks e as peças foram cortadas em MDF em impressora a laser. Nessa etapa, a superfície de partículas já deveria reagir as ações humanas e essa interatividade foi ensaiada manualmente.

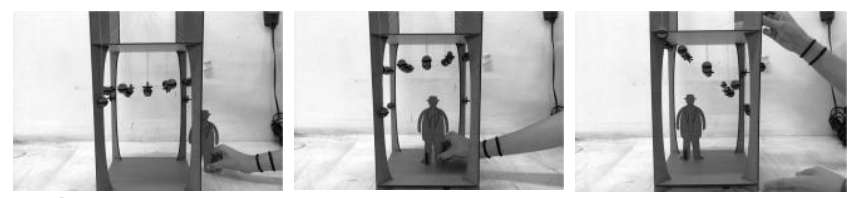

Figura 5: o segundo modelo realizado representa a interação da superfície de partículas com agente.

No terceiro protótipo já era possível reproduzir o comportamento das partículas idealizado pelo grupo. A estrutura foi repensada e produzida nas dimensões que possibilitaram uma interação mais precisa. Os movimentos que representavam a reação da superfície foram mais uma vez efetuados de maneira manual. O material utilizado para a armação e as ferramentas de modelagem e corte foram as mesmas do modelo anterior. As partículas ganharam características físicas importantes como peso e textura e foram representadas por porcas metálicas.

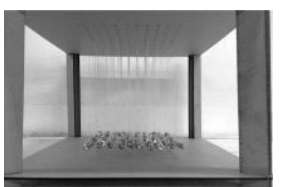

Figura 6: o terceiro modelo reproduz o comportamento da superfície de partículas idealizado.

\section{Testes estruturais: dimensionamento e design}

A estrutura foi se qualificando no decorrer das experimentações feitas nas diferentes maquetes. Para conseguir o movimento ideal das partículas foi necessário duplicar a altura para que os cabos, ora tencionados ora frouxos, pudessem de movimentar adequadamente. Também, deveria garantir certo afastamento das arestas da instalação para que o ponto central ao se mover tivesse máxima tensão permitindo um posicionamento lateralizado da parábola.

A escolha do afastamento e da quantidade dos furos se deu pela percepção da união das partículas formando uma superfície. A dimensão do diâmetro do furo deveria ser grande o suficiente para o fio se movimentar e não rasgar ou prender. As esferas foram escolhidas a partir do peso que exerciam sobre o fio mantendo-o esticado, visto que sem isso o movimento ficaria prejudicado. $O$ fio foi escolhido pela transparência, a intenção era fazer com que este desaparecesse. Foram testados diferentes tipos de fios e 0 que determinou a escolha foi a espessura, a resistência ao atrito causado pelo movimento e ao peso das partículas, a pouca capacidade de elasticidade e a não deformação da estrutura do fio no decorrer da interação.

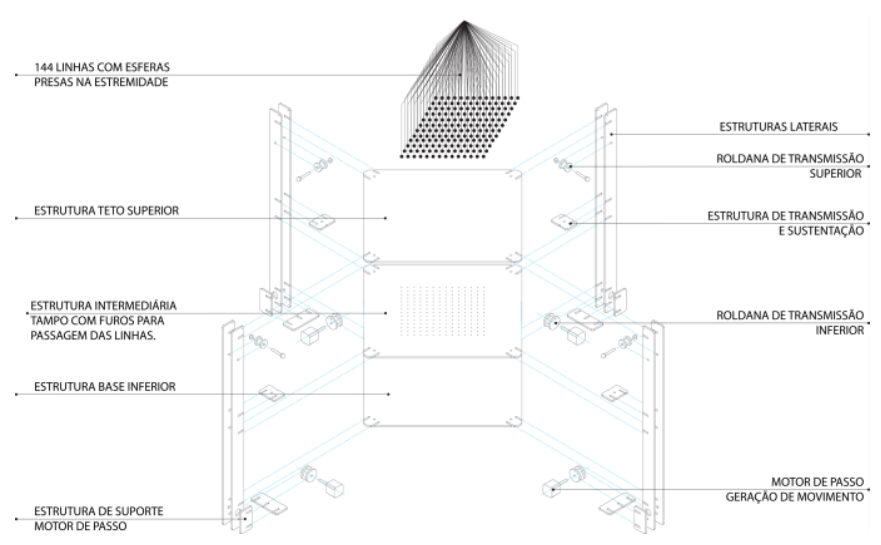

Figura 7: axonométrica explodida do artefato.

\section{Testes mecânicos: motores e roldanas}

Os artefatos estudados como referência para o movimento das partículas dispunham de muitos motores para reproduzir a dinâmica idealizada. A maneira encontrada pelo grupo para otimizar essa quantidade foi reunir o prolongamento dos fios que fixavam cada partícula num único ponto e a partir desse ponto, conectar os motores através de cabos.

Os testes realizados nessa etapa tinham como objetivo avaliar tanto a quantidade de motores mínima necessária quanto a potência que cada um deveria exercer. Foram então instalados quatro motores de passo auxiliados por roldanas para melhorar o desempenho da tração dos fios. 0 
distanciamento entre os pontos de tração foi calculado para possibilitar a deformação máxima da superfície de partículas.

\section{Sistema eletrônico: softwares e hardwares}

O projeto, inicialmente desenvolvido a partir de maquetes, foi modelado virtualmente após observadas algumas escolhas de proporções e quantidade de partículas. A combinação dos softwares Rhinoceros e Grasshopper permitiu estudos paramétricos destas variações o que direcionou algumas escolhas no projeto final. A virtualização permitiu a simulação da interação proposta, visto que o sistema de sensor no Arduino transferia informações da proximidade do individuo para a estrutura virtual. A programação do Arduino teve uma base simples que consistia no reconhecimento do agente no espaço e o cálculo da variação da proximidade deste com as partículas as quais eram repelidas por ele gerando uma formação parabólica na superfície interativa.

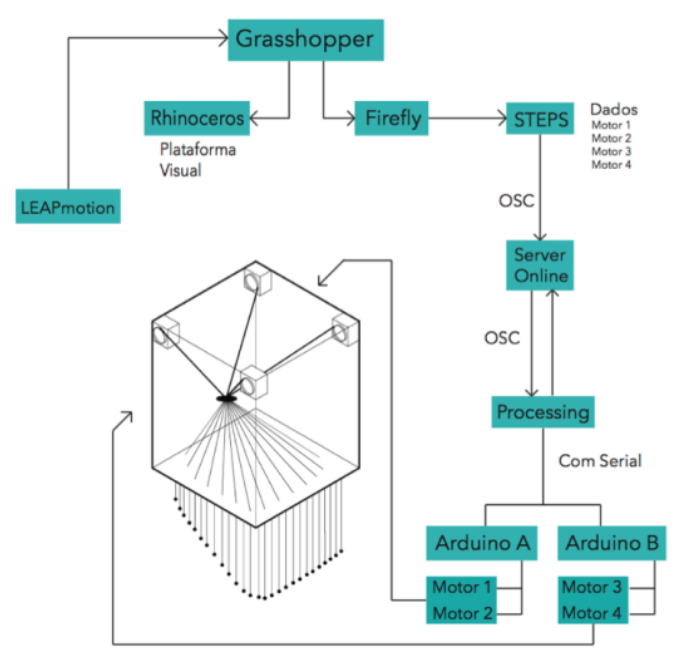

Figura 8: sistema de interação entre o software e o hardware.

O desafio foi fazer com que o Arduino reconhecesse os códigos enviados pelo sensor e os transformassem em movimento dos quatro motores responsáveis pela mecânica do sistema desenvolvido. A escolha por usar dois Arduinos, cada qual com um shield acoplado para conectar dois motores, otimizou o sistema.

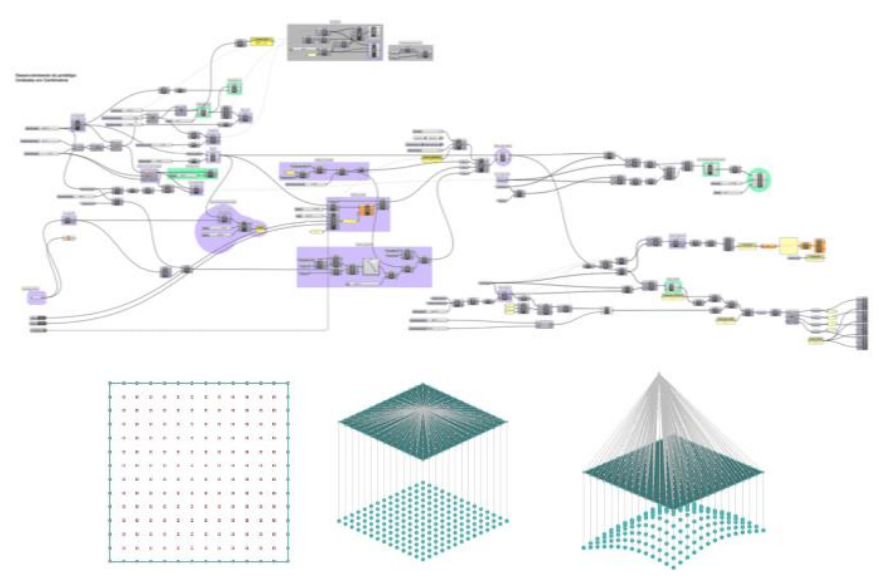

Figura 9: algoritmo e modelo.

\section{Meios de interação: testes de sensores}

$\mathrm{O}$ teste foi realizado inicialmente com um mini Kinect e o sistema foi modelado digitalmente. O objetivo era interferir na formação da parábola de acordo com a proximidade do individuo virtual controlado pela mão. Posteriormente, com a necessidade de interagir o modelo de acordo com a proximidade do individuo real, foi escolhido o sensor infravermelho, o qual calculou a distância da pessoa em relação ao modelo mecânico e interagiu movimentando suas partículas imediatamente.

\section{0 artefato responsivo}

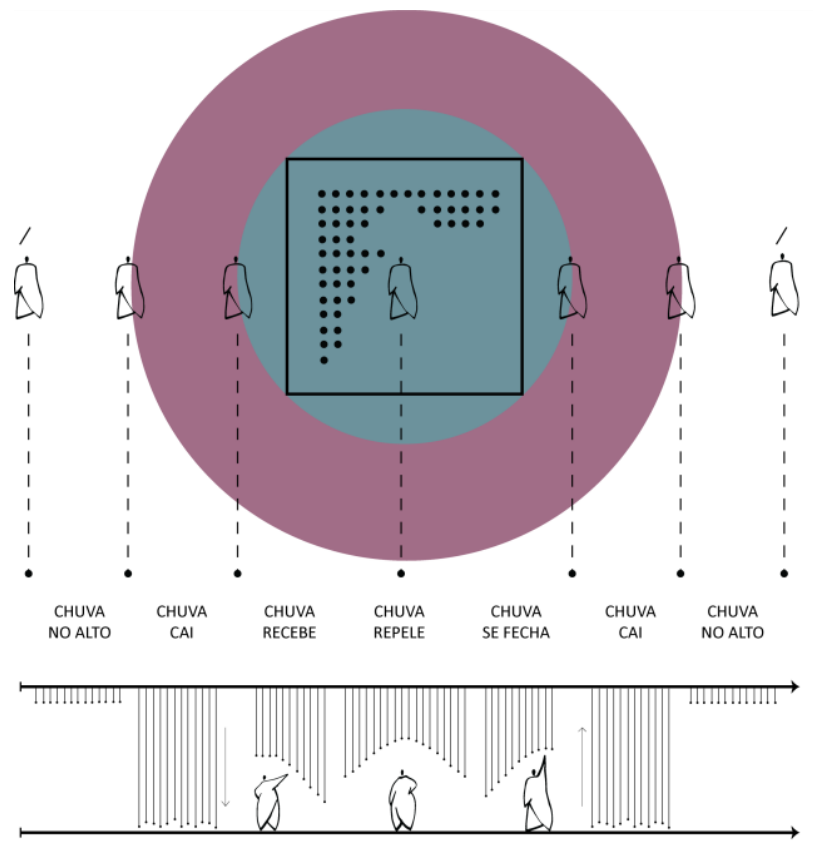

Figura 10: esquema dos raios de atuação da interação.

\section{Funcionamento}

Antes do agente se aproximar dos raios de interação, as esferas estão situadas em sua altura máxima, ou seja, posicionadas na maior tração possível dos fios. Quando o agente se aproxima do primeiro raio de atuação, os sensores são ativados e as esferas caem de maneira a surpreender quem está chegando perto. Ao se aproximar do segundo raio de atuação, parte das esferas se levantam para convidar a pessoa a interagir com a instalação. Em seguida, as esferas são repelidas de acordo com os movimentos do agente no espaço.

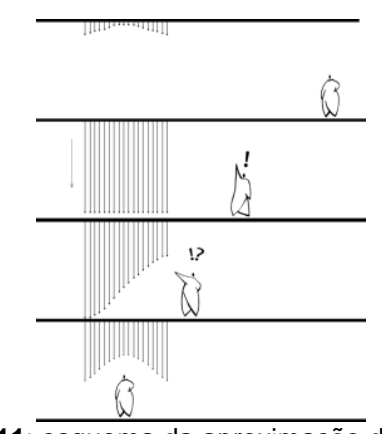

Figura 11: esquema da aproximação do agente. 


\section{Resultados e discussão}

A ação de decidir é fundamental no projeto, pois está associada com seu objetivo final: descrever de que modo um objeto desempenha uma função. Mas como o projeto é uma idealização de um acontecimento, pode-se pensar em termos de formulação de hipóteses (Kowaltowski, 2011). Ou seja: uma vez que o projetista opta por uma, ele formula uma hipótese de como o projeto vai se resolver. A decisão de considerar 0 antropocentrismo como condicionante do caráter responsivo motivou o desenvolvimento da instalação proposta.
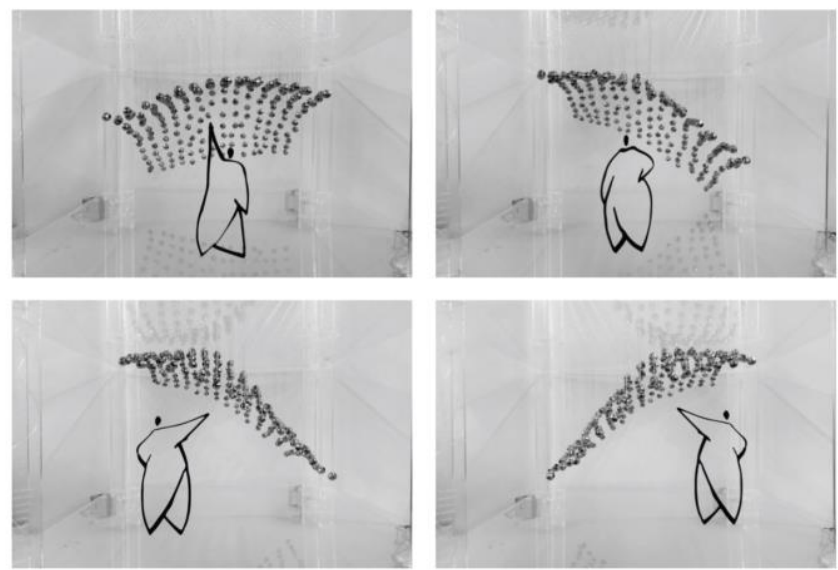

Figura 12: deformações responsivas - interação com o modelo final.

$\mathrm{O}$ artefato, atualmente na escala de protótipo, interage com o individuo. O modelo final possibilitou 0 movimento das partículas conforme a aproximação do agente ativo e os raios de atuação foram adaptados para simular o movimento idealizado para escala humana. O sucesso do resultado final do workshop motivou o grupo a dar continuidade ao projeto e hoje almeja desenvolve-lo em escala 1:1 para permitir, de fato, a interação humana dentro do espaço configurado pelo elemento. A busca por materiais e mecanismos apropriados, assim como a adaptação do sistema estrutural para escala humana, têm impulsionado a investigação de como concretizar essa ideia. O grupo hoje desenvolve uma pesquisa interdisciplinar com 0 auxílio de designers, engenheiros e profissionais e estudantes de arquitetura.

\section{Agradecimentos}

A todos envolvidos no workshop, ao LAMO e a FAU-UFRJ.

\section{Referencias}

Bruscato, U. M. Práticas digitais na arquitetura: seis experiências internacionais. Arquitetura revista. Unisinos, São Leopoldo, 2011.

Couto, H. Ecolinguística. Cadernos de linguagem e sociedade, 10. 2009. 125-149.

Henriques, G. Sistemas responsivos: relevância, estado da arte e desenvolvimentos. Proceedings XIX Congresso da Sociedade Ibero-americana de Gráfica Digital (SIGRADI), Santa Catarina, 2015, 200-206.

Kowaltowski, D., Moreira, D., Petreche, J., Fabrício, Márcio. (2011). $O$ processo de projeto em arquitetura da teoria à tecnologia. São Paulo, SP: Editora Oficina de Textos. 